https://doi.org/10.48009/1_iis_2008_78-86

\title{
LEVERAGING ACADEMIC RESOURCES IN THE ABET ACCREDITATION PROCESS: AN OUTCOME ASSESSMENT INFORMATION SYSTEM
}

\author{
Gina Boff, California University of PA, California, PA USA boff@cup.edu \\ Gary DeLorenzo, California University of PA, California, PA delorenzo@cup.edu \\ Lisa Kovalchick, California University of PA, California, PA kovalchick@cup.edu \\ Paul Sible, California University of PA, California, PA sible@cup.edu
}

\begin{abstract}
The process of ABET accreditation is complex and time consuming. This process often has a larger affect on smaller universities who have limited resources. Small universities must often enlist the help of faculty members in the accreditation process, which reduces the time faculty has to devote to other commitments such as research and teaching. In an effort to circumvent this problem, the Computer Information Systems faculty at California University of Pennsylvania, a small state-system university in southwestern Pennsylvania, has developed an information system called CISaccred. CISaccred was developed to aide in the assessment portion of the accreditation process. This paper provides a follow-up to the original system which resulted from prior research by the faculty. It addresses the insight gained by the faculty from the usage of the application system over a one-year period and identifies those system enhancements that were implemented for the custom-developed assessment system. Also discussed, is the analysis, development and design improvement that warranted the changed enhancements based on insight gained by the faculty.
\end{abstract}

Keywords: assessment tool, accreditation tool, accreditation database, ABET accreditation

\section{INTRODUCTION}

The Computer Information Systems (CIS) faculty at California University of Pennsylvania (CUP) are in the pursuit of ABET accreditation for their Bachelor of Science degree in CIS. CUP is a state-system, liberal arts institution located in southwestern Pennsylvania; as is the case with many small universities seeking ABET accreditation, each of the CIS faculty members at CUP are involved, to varying degrees, in the ABET accreditation process.

While preparing for their first ABET accreditation visit, which will take place in the Fall of 2009, the CIS faculty at CUP were faced with many expectations originating both from administration and from the faculty, themselves. One such administrative goal involved the increase in faculty productivity through increased class sizes. To the CIS faculty, this goal appeared to be in contention with their goal of improving the quality of their CIS program, which would be shown through accreditation from ABET. In an effort to reach both goals, the CIS faculty utilized their skills in order to develop an information system, called CISaccred, to the aide in the assessment portion of the accreditation process. This endeavor resulted in an information system which automated much of the assessment process allowing the CIS faculty to spend more of their time teaching larger class sizes while still maintaining a quality CIS program and working toward the attainment of ABET accreditation.

This paper is a follow up to the previous work entitled "Leveraging Academic Resources in the ABET Accreditation Process: A Case from California University of Pennsylvania" published in Volume 3 of the "Information Systems Education Journal (ISEDJ) in 2008. This follow-up work identifies the insight gained by the CIS faculty at CUP after employing CISaccred over a one year period and identifies processes that were implemented for the custom-developed assessment system. In this paper, we briefly cover the analysis and development of the enhancements, the major functionality of the system enhancements and finally, we close with areas for future growth and improvement.

\section{BACKGROUND}

As described by Boff, DeLorenzo, Kovalchick \& Sible [5], the following excerpt describes the evolution of the CIP into the discovery of a need for an assessment tool to assist with the administrative overhead required:

"Program outcomes were, initially, institutionally defined. Today, however, the Computing Accreditation Commission (CAC) of ABET, Inc. is in the process of instituting a set list of program outcomes in their computing criteria. Approved in 2006 and piloted in the 2007-2008 accreditation cycle, these new outcomes will be mandated by the 2009-2010 accreditation cycle [1] This is because what was once viewed as a seal of approval by institutions of higher education. Booth [4] shows accreditation is becoming more of a mandate as 
'programs are under increasing pressure from [...] institutional review and legislative oversight to demonstrate both responsiveness to, and validity of, curricula in meeting the needs of their target professions'. Thus, in response, Lidtke [12] noted where CAC of ABET revised its accreditation criteria for the computing disciplines and now has a stronger outcomes-based focus. Booth [4] states 'ABET-CAC wants to accredit more programs and encourage innovation; thus, the new standards for computing disciplines contain statements of intent with greater focus on outcomes, assessment and continuous improvement'. The continuous improvement component is paramount to the process and is detailed in a Continuous Improvement Plan (CIP) that each educational program seeking accreditation must devise. The CIP describes how the program intends to continually strive for the full achievement of both the educational objectives and program outcomes. Eventually, proof that the improvement process is being carried out to the extent detailed in the CIP is the final indicator as to whether the program should receive accreditation by ABET.

Still in the process of data collection in preparation for their first ABET-CAC accreditation visit, the faculty teaching in the CIS program offered at CUP quickly realized the rippling effect of such a change as that which is being rolled out in ABET's new program outcomes criteria. Similar to many other universities, CUP's CIP was/is structured in layers, similar to Konsky [11], where:

- Many course objectives may be related to many program outcomes

- Multiple measures with associated rubrics and corresponding benchmarks (performance indicators) are in place for each program outcome

- Many program outcomes may be related to many educational objectives

- Multiple measures with associated rubrics and corresponding benchmarks are in place for each educational objective

Structuring the CIP in layers provides the framework that makes assessment possible. Through a comprehensive curriculum design, the attainment of professional skills and attributes are tracked through performance indicators, also commonly called assessment methods. Blandford [3] notes the achievement of the benchmarks set for these indicators infers that the general program outcome has been attained. In addition, achieving a collection of the program outcomes infers the attainment of one or more educational objectives. This is verified in the post-graduate measuring process for educational objectives and is the point in the CIP where the loop truly is closed, a paramount element in ABET's requirements that the program integrity is en- sured and that potential areas for improvement are identified, per Poger [14].

Booth's [4] statement that 'assessment is difficult and time consuming' is obvious [4]. The initial process of designing a comprehensive curriculum, developing outcomes and objectives suitable to the discipline, and then mapping the curriculum's course objectives to program outcomes and performance indicators, and then mapping program outcomes to educational objectives and their measures required a good deal of research in best practices, documentation and crosschecking and many layers of approvals. The inherent complexity in managing such a system now became evident as the CIS faculty were faced with replacing their 'similar, but not the same' program outcomes with the newly ABET-supplied outcomes. Duff [8] noted it is not just that 'paper-based systems are complex and do not provide immediate feedback”. Blandford's [3] research shows that there is a danger that the burdens of taking on an accreditation process will generate little in the way of meaningful results [3]” [5, 6].

\section{OTHER ASSESSMENT SYSTEMS}

As described by Boff, DeLorenzo, Kovalchick \& Sible (5), the following excerpt summarizes research conducted in search of a pre-existing assessment system that may be acquired for use at CUP:

"First, in terms of commercial systems, there are a multitude of test development utilities and survey development tools available through companies such as Assessment Systems Corporation [2] as well as electronic portfolio solutions and electronic report cards that may be purchased from companies such as Rediker Software [14]; however, nothing in line with a tool for assessment tracking and/or automation was found. Literature searches uncovered tools developed by other institutions, some of these include; however, are not limited to the following.

Clemson University in Clemson, South Carolina, Owens [12] developed a system to assist in the tracking and mapping of course objectives to program outcomes and the measures used for each in their engineering programs. Their system also tracks the educational objectives to their respective measures and reports on the results; however, the relationship between program outcomes and educational objectives was not apparent and reporting was limited to only educational objectives' actual results without comparison to benchmarks.

York College of Pennsylvania in York, Pennsylvania Walcerz [17] developed a system that they call EnableOA. Based on the Principles of Good Practice for Assessing Student Learning, this system tracks program outcomes (referred to as educational outcomes by 
York) for the university's General Education and Mechanical Engineering programs that have been based on the standards set by the American Association for Higher Education and did not address the ABET outcomes assessment CIP.

Iona College in New Rochelle, New York, Poger [13] underwent a three-year development cycle with undergraduate and master's students to develop a system through their computer science capstone courses. The main focus of this system is the collection of student evaluations with relation to each assessment tool used in each course. It then reports as to whether students, in general, felt that they met the objectives related to each course. This clearly did not meet CUP's CIS faculty needs.

Armstrong Atlantic State University in Savannah, Georgia, He [8] developed a system called WEAS (Web-based Educational System) that is used in high school science courses to match teaching assessments to learning assessments. This was, again, out of the scope of CUP's CIS faculty's system objectives.

At Curtin University of Technology in Perth of Western Australia, Konsky [10] is in the process of developing a system that is designed around a layered assessment process similar to ours, except that their mapping occurs from a learning unit (a task) outcome to a course learning outcome and then to a graduate attribute (program outcome). They also assign percentages of contribution that each has to the next and this is the benchmark used in their assessment. This is in line with the Engineers Australia criteria, which is the accreditation being pursued. There is no consideration for post-graduate attributes (educational objectives).

Clayton State University, Morrow Georgia, Booth [4] offers a template for a database developed by one of their IT faculty. As it turns out, the bare bones of CUP's CIS faculty's database design is very similar to theirs; however, CUP's evolved to be a bit more complex due to the need to address the number of many-tomany ( $\mathrm{M}: \mathrm{N}$ ) relationships that exist and the inclusion of educational objectives, the actual scores and benchmarks for both the outcomes and objectives and storage for faculty feedback.

While each of these systems offered some creative insights into ways in which CIS faculty could realize the system objectives, none of them offered enough similarity to be adopted as a starting point, with the exception of Booth's database template. However, given the resource limitation faced as noted in Boff, DeLorenzo, Kovalchick \& Sible $[5,6]$, the CIS faculty pursed an alternative approach in developing a customized application solution. The following discusses the process and enhancements that resulted after using CISaccred during the 2007-2008 academic years" [5, 6].

\section{ANALYSIS, DESIGN AND DEVELOPMENT}

As per Boff, DeLorenzo, Kovalchick \& Sible [5, 6], initially, the CIS faculty designed the CISaccred information system as a typical corporate project with some faculty as project leads, some as users and students in the classroom as the developmental team members. The entire CIP was presented to student teams in a Systems Analysis and Design Course which resulted in a first-pass design solution on both the functionality and relational database design of the CISaccred information system.

Due to some constraints at CUP, platform decisions were made to expedite the development process based on the limited tools and computer systems available at the university. While Oracle 9i with Oracle Forms was considered as an option based on student and faculty knowledge, the option was not used due to university constraints such as remote access usage and configuration setup. As such, it was decided to use Microsoft Access 2007 as the system platform. This met all of the objectives including relational database design, remote access, user friendly interfaces and standard reports.

The data sources, or tables, include master data for information such as courses, faculty, benchmarks, assessment methods, program outcomes and program objectives. Other data source tables include rubric data from the 2007-2008 Senior Project I and Senior Project II courses for outcome assessments for an ethics paper, software engineering research paper, new technology paper and for the capstone information system project, a user manual and demonstration/presentation.

From reviewing some of the initial standard reports, the CIS faculty realized quickly that the information presented did not adequately provide the necessary information to measure assessment to program outcomes and objectives. As an example, the Software Engineering Averages to Benchmark Report noted the benchmarks and student averages for each rubric; however, it did not relate to a program outcome such as Program Outcome OC-B: “An ability to analyze a problem and identify and define the computer requirements appropriate to the solution". Other examples on report inadequacies existed which resulted in a new, different reporting structure for the standard reports. For each report, not only were the assessments for each rubric shown as it related to a Program Outcome, in addition, those assessment calculations were colored coded based on their relationship to the benchmark. Red denotes missed the benchmark significantly to warrant immediate action, yellow denotes missed the bench- 
mark marginally to warrant a trend analysis review, and green denotes met the benchmark. Once the reports are generated, the CIS faculty evaluates whether or not their benchmarks have been met and take corrective action for the appropriate outcome for those benchmarks that warrant attention.

\section{RESULTS}

In the following sections, the overall system schema and the new, enhanced reports are introduced by way of a process flow and narrative. Generally, the paper focuses on baseline functionality provided through the new standard reports and query/search forms.

\section{SYSTEM OVERVIEW}

CISaccred is an information system based on CUP's educational needs assessment for various constituents, which in showed in Figure A-1 in the Appendix. Program objectives are identified, which is describe what students should accomplish within a few years after graduation from the CIS program. Program outcomes are then identified, which describe what students should demonstrate prior to graduation. The outcomes should support the objectives in such a way, that if the students accomplish the outcomes, then it is highly likely that they will achieve the objectives.

Assessment methods are created to measure the various objectives and outcomes. A majority of the assessment methods are in the form of surveys and rubrics. This is where CISaccred assists in the outcomes assessment process, reducing the amount of work required by the CIS faculty members. The rubrics are built into the system as forms in which the instructors of various courses can enter the students' scores. Forms and reports can then be quickly generated to show results for each outcome and objective. The CIS faculty meets to analyze the data, and make decisions as to whether there should be any changes to curriculum, assessment methods, the outcomes assessment process, etc.

\section{FUNCTIONALITY}

CISaccred opens with a switchboard that leads the user into the two, main areas of the system. A user can enter Maintenance to maintain master tables and enter student scores, or enter Reports to access standard reports and query/search forms.

\section{Maintenance}

Data may be entered, modified, and under special circumstances, removed (in most cases, rather than remove data, it would be flagged as inactive, using an "active/inactive" field that has been added to each table). Figure 2 shows the switchboard for the maintenance menu.

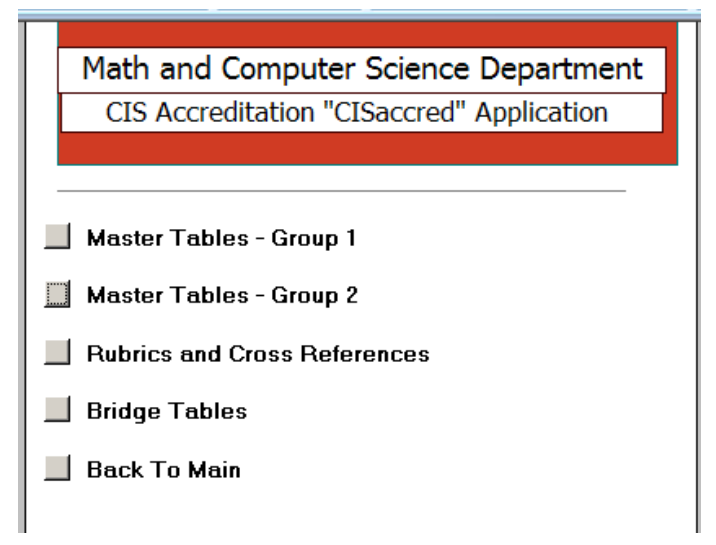

Figure 2: CISaccred Maintenance Switchboard

Maintenance screens are available to maintain master tables, student data and other types of data, as shown in Figures 3 through 5 .

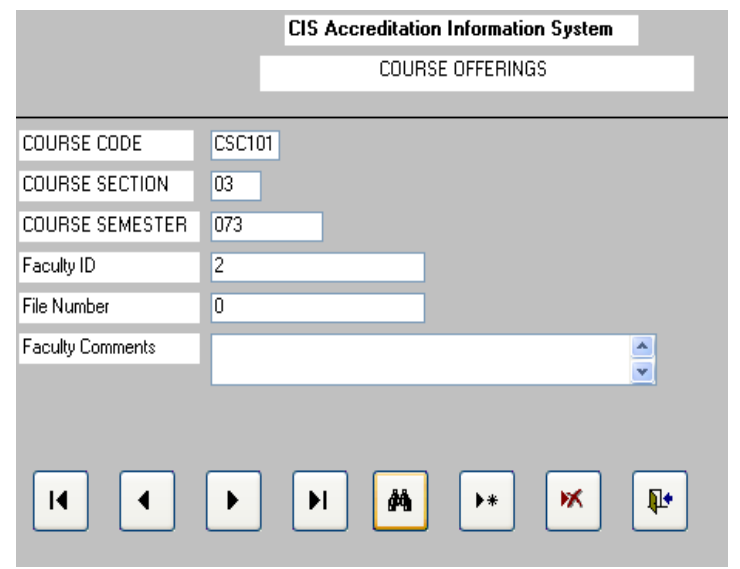

Figure 3: Course Offerings (Master Data) Maintenance 


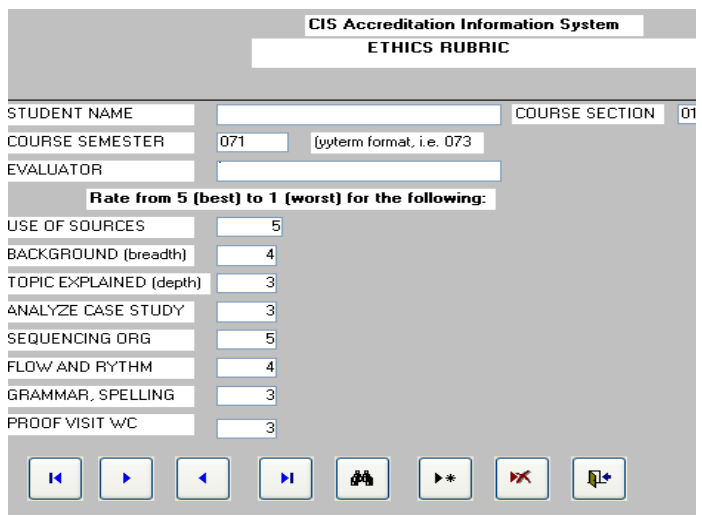

Figure 4: Ethics Rubric Data Maintenance

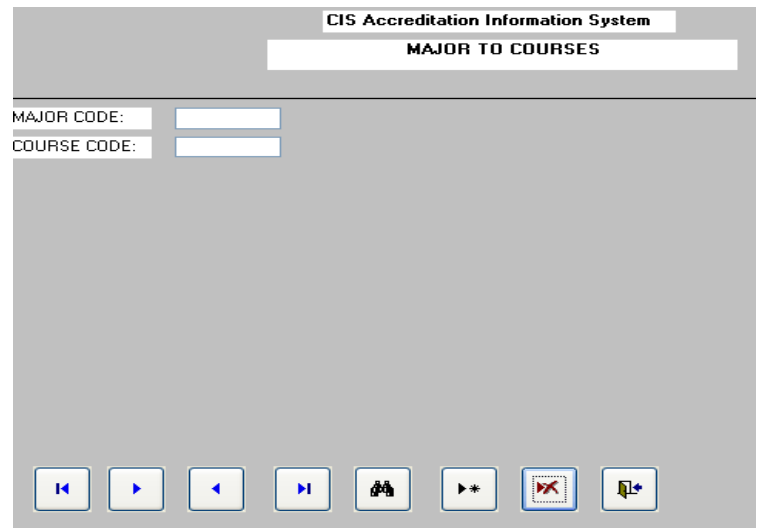

Figure 5: Major to Courses Maintenance

\section{Reports}

Two types of reports may be generated through CISaccred: Descriptive reports and Analytical reports. In addition, there is an interactive form with which a faculty member may view outcomes assessment results for a specific outcome, by selecting an outcome from a drop-down list. A brief description of each along with an example follows.

Descriptive reports: These reports are used to help physically describe the system. They may help one to understand how different parts of the system relate to one another. For example, if a faculty member is teaching a course where assessment is to be carried out, they may generate the Courses to Assessment Methods report in order to identify the assessment activities that they must conduct during the course. The faculty member may then use this report to help plan an outline of semester activities that may be given to the students. The descriptive reports that are currently available include: Program Objectives to Program Outcomes, Courses to Assessment Methods, Program Ob- jectives to Assessment Methods and Program Outcomes to Assessment Methods.

Analytical Reports: This component of CISaccred is where the true beauty and power lie. For each program outcome, rubric scores and the criteria on them are viewed and evaluated, the details of which are institutionally chosen and are not specific to all CIS programs. Benchmarks have been specified as a threshold for achievement or failure and these benchmarks are stored in a maintainable table.

The scores collected through rubrics are tallied (we currently focus on an average for each item) and these results appear on reports along with their associated benchmarks. In this way, there is no extra effort required to gather and manipulate data at evaluation time, except to run and print these reports. The power and ease that this lends to decision making, concerning plans toward continuous improvement cannot be stressed enough.

The reports for Program Outcomes A and B are depicted in Figure A-3 of the Appendix as examples of such reports. They show the course semester, the benchmarks specified as a threshold for achievement or failure and the actual student averages for each item used in assessment of those outcomes for that particular semester. You will note that highlighted colors show that the Learning Experience for the Senior Project, the Support Communications for the Software Engineering Rubric, and the Consistency With Spec, Design Traceability and Consistency With Design for the User Manual Rubric are red (missed significantly). CIS faculty will evaluate the corrective action for those outcomes.

It should be noted that thresholds were identified to determine how close to a benchmark value an average should be to be considered in the 'green', 'yellow', or 'red' area. Missing the benchmark by a certain value, whether high or low, raises a flag. This might seem odd at first, that exceeding a benchmark by 'too much' should raise a flag. However, if you are exceeding your benchmark by a certain threshold, you should consider that, maybe, the benchmark should be raised for that item. Keep in mind that faculty analyze the data and make all decisions (i.e., decision making is not automated in CISaccred).

Assessment Results Form: Another component of CISaccred is similar to the analytical reports, although, it is interactive in nature. As depicted in Figure A-2 of the appendix, a faculty member chooses an outcome, and assessment results for that item are shown. This is another function of CISaccred, beyond standard reports, that provide search and query capabilities for outcomes. 


\section{CONCLUSION}

The CISaccred accreditation tracking tool is useful to the CIS faculty at CUP. However, as with all systems, limitations and areas for improvement have been identified and are being pursued.

The CIS Accreditation Committee, composed of CIS faculty in preparation for an accreditation visit, defined the rubrics for CISaccred. Separately, the outcome results for a particular course are entered by the instructor or Graduate Assistant throughout the semester. Once the data is entered, either at a student or group level depending on the course, the CIS Accreditation Committee reviews the results from the system, utilizing the various reports and forms, to determine any corrections or improvements that are needed for that particular course as it relates to the CIS program.

To date, there are no automatic data feeds into CISaccred. With the help of a Graduate Assistant supporting the CIS faculty, all initial data has been manually entered. Currently, if changes need to be made to any of the existing data, the tables in need of changes must be accessed and manually updated. In addition, we are looking into storing information associated with the CIS program in CISaccred. This would alleviate faculty burdens in maintaining multiple sources of data for curriculum development, course rotations by semester, and having to access multiple data sources, simultaneously, just to advise a student.

In summation, as the CIS faculty members prepare for an on-site CAC of ABET review in the fall of 2009, CISaccred is positioned as an invaluable tool to share our continuous improvement plan and assessment data. As we continue to use the application in preparation for our fall 2009 visit and after we receive feedback from the ABET evaluators on the usage of assessment data through this application, we will address specific enhancements and improvement as needed for CISaccred.

\section{REFERENCES}

1. ABET, Inc. (2007) Criteria for Accrediting Computing Programs. Retrieved April 21, 2007. Available: http://www.abet.org.

2. Assessment Systems (2007) Assessment related software. Retrieved May 15, 2007. Available: http://www.assess.com.

3. Blandford, D.K. and D.J. Hwang (2003) "Five Easy but Effective Assessment Methods." Proceedings of SIGCSE'03, February 19-23, pp. 4144.

4. Booth, L. (2006) "A Database to Promote Continuous Program Improvement.” Proceedings of CITC’07, October 19-21, pp. 83-88.
5. Boff, G., DeLorenzo, G., Kovalchick, L. and Sible, P. (2007) "Leveraging Academic Resources in the ABET Accreditation Process: A Case from California University of Pennsylvania” Proceedings of ISECON (Information Systems Education Conference), November 1-4.

6. Boff, G., DeLorenzo, G., Kovalchick, L. and Sible, P. (2008) "Leveraging Academic Resources in the ABET Accreditation Process: A Case from California University of Pennsylvania”. Information Systems Education Journal (ISEDJ). Volume 3.

7. Challa, C.D. (2005) “The Accreditation Process for IS Programs in Business Schools.” Journal of Information Systems Education, 16(2), 207-216.

8. Duff, J.M. (2004) "Outcomes Assessment across Multiple Accreditation Agencies.” Journal of Industrial Technology, 20(4), 2-7.

9. He, L. and P. Brandt (2007) "WEAS: A Webbased Educational Assessment System.” Proceedings of ACMSE`07, March 23-24, pp. 126-131.

10. Hoffman, T. (1999) Profit Centers vs. Cost Centers, Computerworld, 33(31), 47.

11. Konsky, B., A. Loh, M. Robey, S. Gribble, J. Ivins and D. Cooper (2006) "The Benefit of Information Technology in Managing Outcomes Focused Curriculum Development Across Related Degree Programs.” Proceedings of ACE'06, January 1619, pp. 235-242.

12. Lidtke, D.K., J. Leone and H. Reichgelt (2004) "Computing Accreditation Commission Moves to General and Program Specific Criteria.” Proceedings of 34th ASEE/IEEE Frontiers in Education Conference, October 20-23.

13. Owen, C., K. Scales and M. Leonard (1999) "Preparing for Program Accreditation Review under ABET Engineering Criteria 2000: Creating a Database of Outcomes and outcome Indicators for a Variety of Engineering Programs.” Journal of Engineering Education, 88(3), 255-259.

14. Poger, S., R. Schiaffino and C. Ricardo (2005) “A Software Development Project: A StudentWritten Assessment System.” Journal of Computing Sciences, 20(5), 229-238.

15. Rediker Software, Inc. (2007) Assessment related software. Retrieved May 15, 2007. Available: http://www.rediker.com.

16. Rob P. and C. Coronel (2007) Database Systems Design, Implementation, and Management. Boston: Thomson Course Technology. 
17. Rogers, G. (2004) Portfolios: The Tool that Rocks. Retrieved July 17, $2007 . \quad$ Available: http://www.abet.org/ Linked\%20DocumentsUPDATE/ Assessment/Portfolios\%20Rock_handouts.pdf.

18. Walcerz, D.B. (1999) "EnableOA: A SoftwareDriven Outcomes Assessment Process Consistent with the Principles of Good Practice for Assessing Student Learning." Proceedings of ASEE midAtlantic Conference, April 17, pp. 30-39.

\section{APPENDIX}

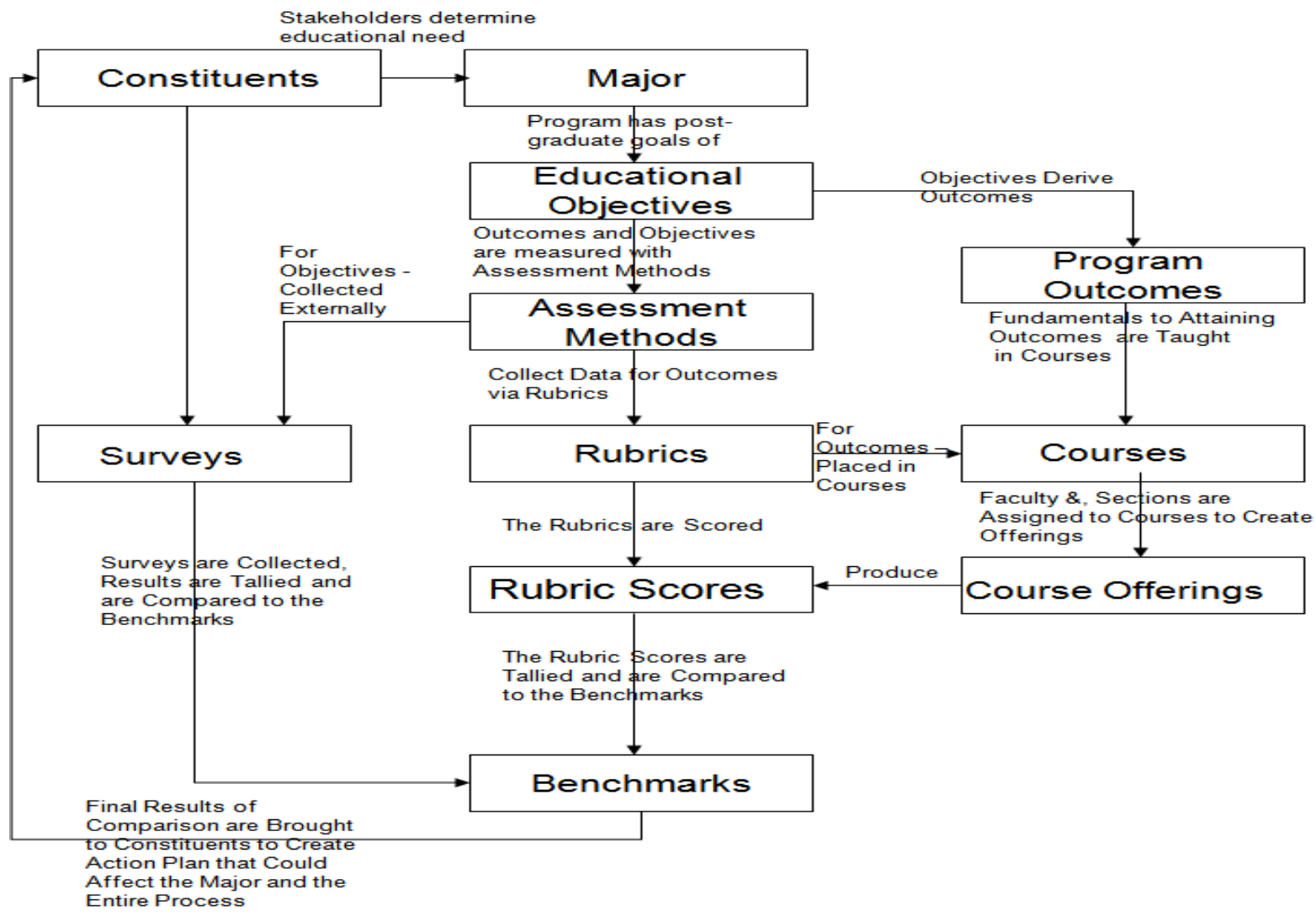

Figure A-1: CISaccred Process 


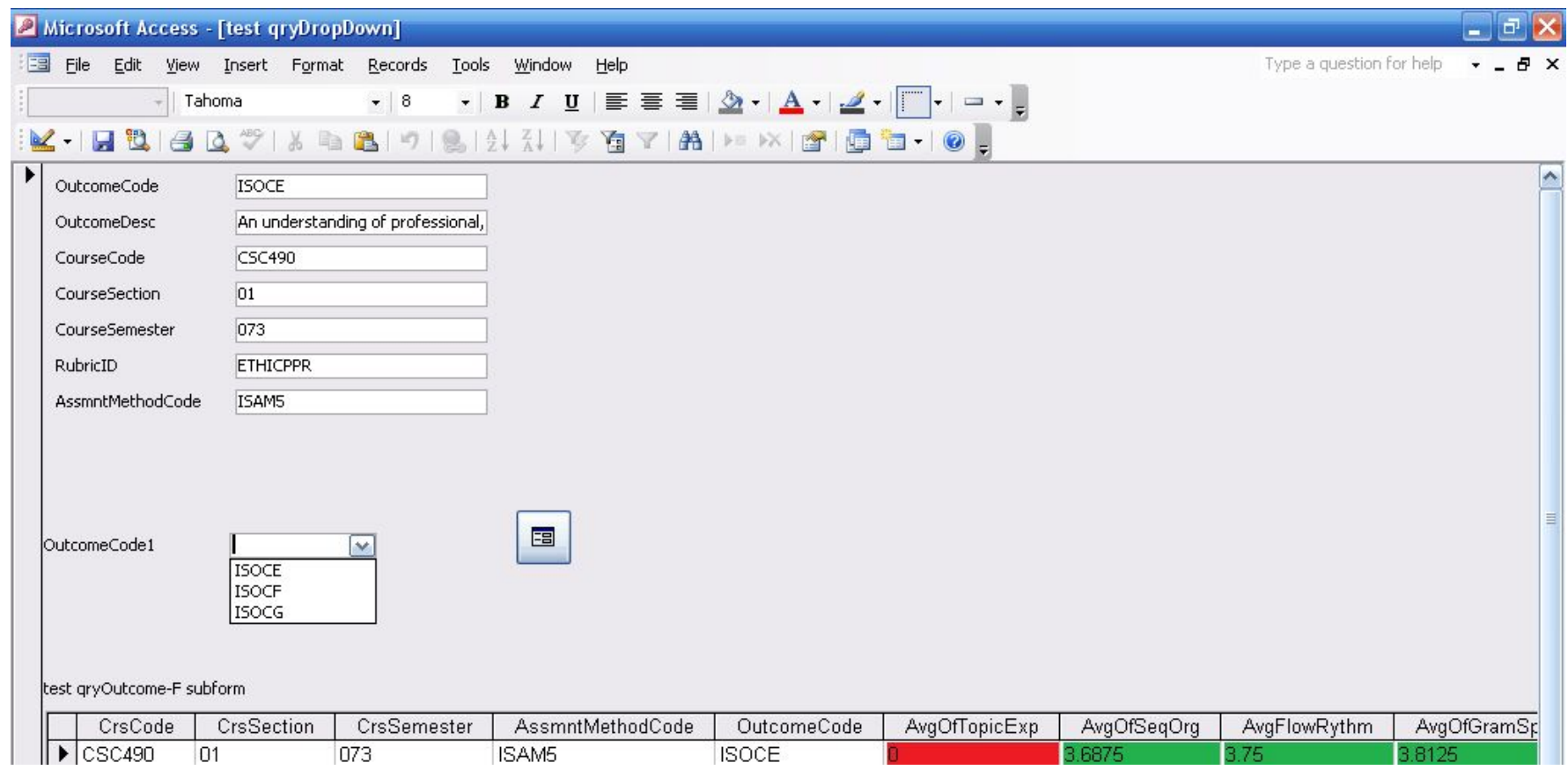

Figure A-2: Outcome Results Form

Outcome OC-A : An ability to apply knowledge of computing and mạth appropriate to the discipline

\begin{tabular}{|l|l|c|}
\cline { 2 - 3 } Senior Project Rubric & ClearStatement & 3 \\
\cline { 2 - 3 } & DefinedPriorExperience & 3 \\
\hline & TechnologyRelated & 2 \\
\hline \multirow{4}{*}{ Graduating Student Survey } & TechnologyChosen & 2 \\
\hline & LearningExperience & 5 \\
\cline { 2 - 3 } & ChoiceofTechnology & 4 \\
\cline { 2 - 3 } & SequencingOrganization & 4 \\
\cline { 2 - 3 } & FlowRythm & 3 \\
\hline & GrammarSpelling & 3 \\
\hline & UseofSources & 4 \\
\hline
\end{tabular}



Outcome OC-B : $\begin{aligned} & \text { An ability to analyze a problem and identify and define the } \\ & \text { computing requirements appropriate to its solution }\end{aligned}$

\begin{tabular}{|l|l|c|}
\cline { 2 - 3 } Software Engineering Rubric & Contribute Knowledge & 4 \\
\cline { 2 - 3 } & Tasks On Time & 3 \\
\cline { 2 - 3 } & Well With Others & 3 \\
\hline & Support Communication & 5 \\
\hline \multirow{4}{*}{ User Manual Rubric } & Quality of Interview & 3 \\
\hline & Clarity of Document & 3 \\
\hline & Identify Problem & 2 \\
\cline { 2 - 3 } & Consistencywith Spec & 1 \\
\hline & Efficiency of Solution & 3 \\
\cline { 2 - 3 } & Design Traceability & 5 \\
\hline & Consistency with Desigr & 5 \\
\hline & Correctness of Solution & 4 \\
\hline & Success of Project & 4 \\
\cline { 2 - 2 } &
\end{tabular}

4

Figure A-3: Analytical Reports 